\title{
CHANNEL CHOICE AND COORDINATION OF FRESH AGRICULTURAL PRODUCT SUPPLY CHAIN
}

\author{
Bo YAN*, Jing FAN AND Ji-WEN WU
}

\begin{abstract}
By constructing a dual-channel fresh agricultural product (FAP) supply chain consisting of a retailer and a supplier, this paper considers the effect of fresh-keeping level on the freshness of perishable products and constructs a time-varying demand function based on freshness. The operating cost of the internet channel to the supplier has also been considered in the model. Optimal pricing strategy and profits of supply chain members under dual channels are investigated respectively in this paper. Comparing the optimal profit under traditional single-channel and dual-channel supply chain, we obtain the condition that the internet operating cost should satisfy. Given the situation where the supplier obtains profit while the retailer loses after the supplier introduced the internet channel, this paper proposes a revenue-sharing contract to make up for the loss of the retailer and achieves a win-win situation. Research shows that in the numerical analysis the supplier's and the retailer's profit can only be improved when the operating cost of the internet channel $c_{0}$ and revenue-sharing ratio $\psi$ are within a certain range. When $\psi \geq 0.4$ and $0 \leq c_{0} \leq \sqrt{\frac{2.34 \psi^{2}+1.25 \psi+7.39}{8.43 \psi^{3}+4.62 \psi^{2}+5.72 \psi+9.05}}+8.64$, Pareto improvement will be attained on both sides in the supply chain.
\end{abstract}

Mathematics Subject Classification. 90B50.

Received May 16, 2020. Accepted January 25, 2021.

\section{INTRODUCTION}

As e-commerce develops rapidly and consumers' Internet consumption consciousness upgrades, circulating channels and structure of fresh agricultural products (FAPs) are shifting accordingly. A growing number of companies reckon internet marketing channel as a supplement to traditional marketing channel. However, if the supplier introduces the internet channel, the competition between the supplier and the retailer will be intensified, resulting in double marginalization, and shrinking profits for supply chain members. Hence, whether to introduce the internet channel or not is a strategic decision-making to the supplier in a fresh agricultural product (FAP) supply chain. Moreover, some other important factors should also be taken into consideration for channel choice. For one thing, due to the lack of sales experience and understanding of customers accumulated by the retailer for many years, so introducing the internet channel will occupy the supplier's internet operating cost

Keywords. Fresh agricultural product (FAP) supply chain, channel choice, fresh-keeping effort, Internet operating cost, revenuesharing contract.

School of Economics and Finance, South China University of Technology, Guangzhou 510006, PR China.

*Corresponding author: yanbo@scut.edu.cn 
(including market research, marketing promotion, etc.). For another, agricultural products feature a short shelflife, difficult to preserve and highly perishable, freshness is another important factor that will affect consumer purchasing behavior apart from price. Therefore, the supplier has to invest in preservation technology to slow down the decline of freshness of agricultural products. To sum up, when it comes to introducing the internet channel, the supplier should consider internet operating cost and fresh-keeping cost.

Some literatures have studied the channel development mode of FAP supply chain. Mueller and Rolf [10] analyzed the effect of e-commerce on agricultural products market from the aspects of supply chain and value chain. Chiang et al. [5] were the earliest one to verify that the introduction of direct channels by manufacturers based on their traditional channels would help manufacturers to improve their overall profitability even if no sales activities take place in direct channels through theoretical model. Lu and Chen [9] found when the manufacturer resells products to consumers through e-commerce, on the one hand, it can attract Internet shoppers to purchase through the physical channel; on the other hand, it can effectively reduce the dual marginalization problem caused by the introduction of the internet channel. Albert et al. [1] discussed the feasibility of developing direct marketing channels for manufacturers when product quality is different through different channels. Abhishek et al. [2] studied a dual-channel supply chain consisting of a manufacturer, a physical store and two online retailers, and discussed the influence of different sales modes (reselling and agency selling) of e-commerce, the degree of competition between e-commerce and the demand spillover effect of online channel on the operation strategy of supply chain.

Many scholars have studied the pricing and competition of dual-channel FAP supply chain based on different situations. Zhang and Wang [17] studied a retailer introducing the online channel and the traditional channel to sell a short-life-cycle product in different periods, and they also studied different pricing mechanisms to solve channel conflict. Panda et al. [11] explores pricing and replenishment policies for a high-tech product in a dualchannel supply chain, considering reduction of the unit cost of the product in a short life cycle. Roy et al. [14] established a dual-channel model for a two-echelon supply chain composed of one manufacturer and one retailer for trading a single product, and obtained optimal stock level, sales prices, promotional effort and services level in the integrated system and Stackelberg game framework. Zhao et al. [18] employed lateral inventory transshipment to reduce inventory risk and strengthen dual channel cooperation in OTO (online-to-offline) supply chain.

In addition, many scholars have studied the coordination of dual-channel FAP supply chain in different situations. Cai et al. [3] studied how a seller should design the prices and qualities of products of dual-channel supply chain when facing consumers with probabilistic purchasing behavior, considering three schemes under personalized offering: independent pricing, revenue sharing and profit sharing. Li et al. [8] explored the decisionmaking problem of dual-channel supply chain, when the manufacturer sells a high-quality product through the traditional channel and sells a similar but lower-quality product through a direct channel. And they considered the effect of the personalized pricing strategy and a Money-Back Guarantee on channel decision and supply chain coordination. Wang et al. [16] analyzed a manufacturer's e-channel decision problem in which the manufacturer selects a direct-sales channel or a third-party consignment channel. Chen et al. [4] studied the pricing strategy under conventional reselling or novel agency selling pattern when online retail channel is chosen.

The researches on freshness-keeping investment have become a hot topic. Lee and Dye [7] constructed the deteriorating inventory model of demand-dependent inventory, and took the inventory costs as the decision variable and solved the optimal inventory plan and freshness-keeping investment. Piramuthu et al. [12] used item-level information for the quality of perishables through RFID (Radio Frequency Identification) technology and considered perishable inventory management with the demand that is directly dependent on the amount of shelf-space as well as freshness. Zheng et al. [19] compared the performance of the supply chain under the costs-sharing contract with that under the revenue-sharing cost-sharing contract when the manufacturer keeps the products fresh. Song and He [16] studied the freshness level and pricing strategy in a three-layer FAP supply chain that consists of a fresh products e-commerce enterprise, third-party logistics service provider and community convenience store. Roy and Giri [13] proposed a composite contract composed of sales rebate and 


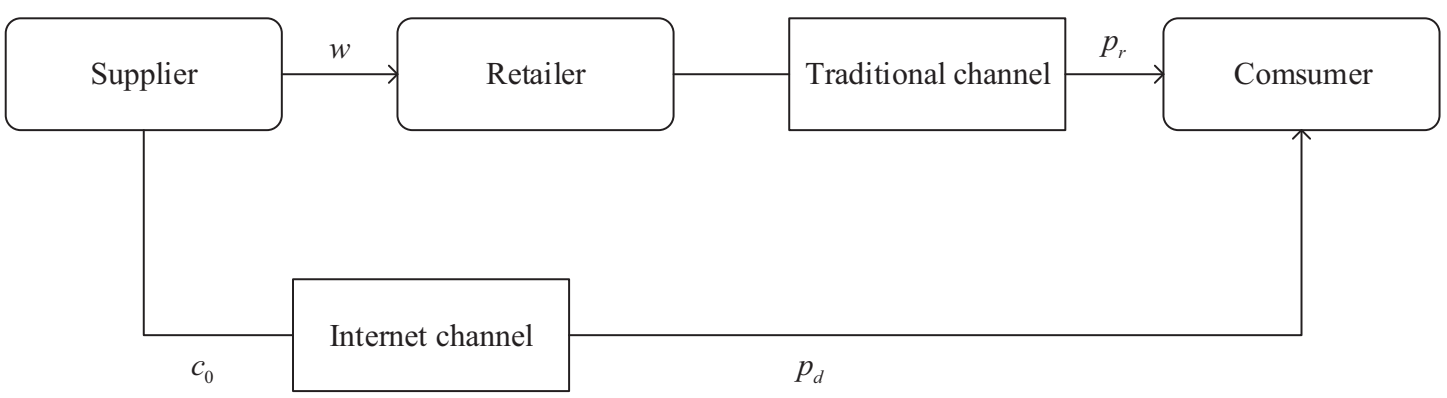

FiguRE 1. Structure of dual-channel supply chain.

penalty (SRP) to coordinate system. Gu et al. [6] considered quality-improvement effort and fresh-keeping effort in the centralized model and two decentralized models.

To sum up, scholars have made some valuable research results in the dual-channel supply chain. Most articles do not consider the loss of freshness and neglect the factors such as the internet channel operating cost paid by the supplier. Therefore, this paper explores the best channel selection strategy of fresh enterprises and the operating cost conditions when the supplier introduces the internet channel.

\section{Problem Description AND hypotheses}

This paper studies decision-making in a FAP supply chain which consists of an agricultural cooperative and a traditional supermarket. In the dual-channel supply chain, the supplier has his own electronic commerce channel and acts as an online retailer. In this study, we assume that the supplier only provides one kind of FAP. In a traditional single-channel supply chain, the retailer will buy the product from the supplier with wholesale price $w$ and sell it with retail price $p$. In a dual-channel supply chain, the supplier sells FAP directly to consumers through the internet channel with $p_{d}$; the retailer will buy the product from the supplier with wholesale price $w$ and sell it with $p_{r}$. Because the supplier lacks sales experience and understanding of customers, we assume that the operating cost of internet channel is $c_{0}$. The structure of a dual-channel supply chain is shown in Figure 1.

To make the model more practical, we propose the following assumptions:

(1) For calculation convenience, we assume that the production cost of FAP is zero.

(2) The supplier and the retailer are risk-neutral; therefore, they make decisions for their own maximum profit.

(3) The surplus value of FAP after the end of the life cycle is 0 , the shortage is negligible;

(4) The free-rider effect between channels is negligible;

(5) The retailer can't purchase products from the internet channel.

By referring to the literature of Zheng et al. [19], we define the freshness function as $\lambda_{\eta}(t)=u_{0}-u_{\eta}\left(\frac{t}{T}\right)^{1 / 2}$, where $u_{0}$ denotes the initial freshness level of agricultural product and $u_{\eta}$ denotes the impact of freshness on time sensitivity coefficient, i.e., the deterioration rate. $\eta=1,2$ represents the time it takes for FAP to reach customers via the traditional channel or the internet one.

Suppose the demand function is linear and freshness factor has been considered, the time-dependent demand function of the traditional channel is given by

$$
D_{1}(t)=\theta a-p_{r}+b p_{d}+\beta \lambda_{1}(t)+\varepsilon
$$

and the demand function of the internet channel is given by

$$
D_{2}(t)=(1-\theta) a-p_{d}+b p_{r}+\beta \lambda_{2}(t)+\varepsilon .
$$


TABLE 1. Symbols and definitions.

\begin{tabular}{ll}
\hline \hline Symbols & Definition \\
\hline$a$ & Potential market of FAP \\
$p$ & Traditional single-channel retail price of FAP \\
$p_{r}$ & Traditional channel retail price of FAP \\
$p_{d}$ & Internet channel retail price of FAP \\
$b$ & The sensitivity coefficient of market demand to price of another channel \\
$w$ & Wholesale price \\
$c_{0}$ & Internet operating cost \\
$D$ & Demand of traditional single-channel \\
$D_{1}$ & Demand of traditional channel \\
$D_{2}$ & Demand of the internet channel \\
$\theta$ & Market share proportion of traditional channel after the introduction \\
& of the internet channel \\
$u_{0}$ & Initial freshness level of FAP \\
$u$ & Deterioration rate (decay rate) of FAP \\
$T$ & The single sales period, less than life cycle of FAP; $t \in[0, T]$ \\
$\psi$ & Revenue-sharing ratio of the supplier \\
$i$ & $i=m, r$ denotes the supplier the retailer respectively \\
$j$ & $j=Y, N$ indicates the dual-channel supply chain and traditional single \\
$\pi_{i}^{j}$ & supply chain respectively \\
$\Delta \pi_{i}^{j}$ & Profit of supply chain member $i$ under the situation $j$ \\
& Profit gap of supply chain member $i$ before and after the introduction \\
\hline & of the internet channel \\
\hline
\end{tabular}

Notes. Superscript $*$ marks the optimal result of traditional single-channel or dual-channel FAP supply chain.

In traditional single-channel, the expression of demand function is

$$
D(t)=a-p+\beta \lambda_{1}(t)+\varepsilon .
$$

Generally, if $b<1$, the impact of the channel price on market demand is greater than that of other prices. If we define $\beta$ as consumers' sensitivity to the product's freshness, as freshness increases every unit, both online and offline demand increase by $\beta . \varepsilon$ is a random variable satisfying $E(\varepsilon)=0$, $\operatorname{Var}(\varepsilon)=\sigma^{2}$. Symbols used in this paper and their definitions are shown in Table 1.

\section{FAP SUPPLY CHAIN DECISION-MAKING MODEL}

The optimal decisions of FAP under traditional single-channel and under dual-channel are respectively obtained. Through comparing the situation before and after the introduction of the internet channel, it is easy to find some theoretical results.

\subsection{Traditional single channel decision-making model of FAP}

When the supplier has not yet introduced the internet channel, the expected profit of traditional retailer is expressed as

$$
\begin{aligned}
\pi_{r}^{N} & =(p-w) \frac{1}{T} \int_{0}^{T} D(t) \mathrm{d} t \\
& =(p-w) \frac{1}{T} \int_{0}^{T}\left(a-p+\beta\left(u_{0}-u_{1}\left(\frac{t}{T}\right)^{1 / 2}\right)\right) \mathrm{d} t .
\end{aligned}
$$


If the average demand in a single cycle is regarded as the market demand, then the optimal retail price of the retailer is given by

$$
p^{N^{*}}=\frac{a-w}{2}+\frac{\beta\left(3 u_{0}-2 u_{1}\right)}{6} .
$$

Here, the expected profit of the supplier is expressed as

$$
\begin{aligned}
\pi_{m}^{N} & =w \frac{1}{T} \int_{0}^{T} D(t) \mathrm{d} t \\
& =w \frac{1}{T} \int_{0}^{T}\left(a-p+\beta\left(u_{0}-u_{1}\left(\frac{t}{T}\right)^{1 / 2}\right)\right) \mathrm{d} t .
\end{aligned}
$$

Thus, we obtain the optimal wholesale price and retail price of FAP respectively as:

$$
\begin{aligned}
& w^{N^{*}}=\frac{3 a+3 \beta u_{0}-2 \beta u_{1}}{6} \\
& p^{N^{*}}=\frac{3 a+3 \beta u_{0}-2 \beta u_{1}}{4} .
\end{aligned}
$$

Substituting $w^{N^{*}}$ and $p^{N^{*}}$ into equations (3.1) and (3.3), the optimal expected profits of the retailer and the supplier are respectively expressed as:

$$
\begin{aligned}
& \pi_{r}^{N^{*}}=\left(\frac{3 a-2 \beta u_{1}+3 \beta u_{0}}{12}\right)^{2} \\
& \pi_{m}^{N^{*}}=\frac{\left(3 a-2 \beta u_{1}+3 \beta u_{0}\right)^{2}}{72}
\end{aligned}
$$

We can find there is a certain proportion between the retailer's profit and the supplier's profit. $\frac{\pi_{r}^{N^{*}}}{\pi_{m}^{N^{*}}}=36$, as the leader of the supply chain, the retailer can make more profits in the whole supply chain.

The market demand of FAP is given by

$$
D^{N^{*}}=\frac{3 a+3 \beta u_{0}-2 \beta u_{1}}{12} .
$$

\subsection{Dual-channel decision-making model of FAP}

As the supplier is planning to introduce the internet channel, because of insufficient information about the internet channel market, the supplier needs to pay the internet channel operating cost $c_{0}$ to support internet marketing, internet operation, and relevant services. When the supplier becomes dominant in the dual-channel FAP supply chain, Stackelberg game means that firstly the supplier makes pricing decisions according to the market information, then the retailer makes decisions according to the supplier. In this section, using backward induction, we can find the response function of the retailer firstly, then get the optimal wholesale price and internet price. The optimal pricing decision of the retailer is decided by equation (3.9).

To begin with, the expected profit of the retailer is expressed as:

$$
E\left[\pi_{r}\right]=\left(p_{r}-w\right) \frac{1}{T} \int_{0}^{T}\left(\theta a-p_{r}+b p_{d}+\beta\left(u_{0}-u_{1}\left(\frac{t}{T}\right)^{1 / 2}\right)\right) \mathrm{d} t .
$$

The expected profit of the supplier is:

$$
\begin{aligned}
E\left[\pi_{m}\right]= & w \frac{1}{T} \int_{0}^{T}\left(\theta a-p_{r}+b p_{d}+\beta\left(u_{0}-u_{1}\left(\frac{t}{T}\right)^{1 / 2}\right)\right) \mathrm{d} t \\
& +\left(p_{d}-c_{0}\right) \frac{1}{T} \int_{0}^{T}\left[(1-\theta) a-p_{d}+b p_{r}+\beta\left(u_{0}-u_{2}\left(\frac{t}{T}\right)^{1 / 2}\right)\right] \mathrm{d} t
\end{aligned}
$$


which contains wholesale revenue from traditional channel and retail revenue from the internet channel. According to the backward induction method, the pricing behavior of the retailer is studied first.

(1) Pricing decision of the retailer.

Based on previous assumptions, the optimal decision function of the retailer is $\max \pi_{r}^{Y}$. Given $p_{d}, w$ of the supplier, we solve the optimal retail price of traditional channel. Taking the first derivative from the retailer's profit function, we obtain $\frac{\partial \pi_{r}}{\partial p_{r}}=w+b p_{d}-2 p_{r}+a \theta+\frac{\beta\left(3 u_{0}-2 u_{1}\right)}{3}$, and its second derivative satisfies $\frac{\partial^{2} \pi_{r}}{\partial p_{r}^{2}}<0$. Thus the retailers' profit has a maximum value when $\frac{\partial \pi_{r}}{\partial p_{r}}=0$, then the optimal price is given by $p_{r}^{*}=\frac{3 w+3 b p_{d}+3 a \theta+3 \beta u_{0}-2 \beta u_{1}}{6}$, and the optimal profit function of the retailer is expressed as $\pi_{r}=\left(\frac{3 w-3 b p_{d}-3 a \theta-3 \beta u_{0}+2 \beta u_{1}}{6}\right)^{2}$.

(2) Pricing decision of the supplier.

The optimal decision function of the supplier is expressed as:

$$
\begin{aligned}
\pi_{m}^{Y}= & \left(c_{0}-p_{d}\right)\left(p_{d}+a(\theta-1)-\frac{3 \beta u_{0}-2 \beta u_{2}}{3}-b \frac{3 w+3 b p_{d}+3 a \theta+3 \beta u_{0}-2 \beta u_{1}}{6}\right) \\
& -w \frac{3 w-3 b p_{d}-3 a \theta-3 \beta u_{0}+2 \beta u_{1}}{6} .
\end{aligned}
$$

Taking first derivatives of $p_{d}, w$ respectively, we obtain

$$
\begin{aligned}
\frac{d \pi_{m}^{Y}}{d p_{d}} & =b w+b \frac{3 b p_{d}+3 a \theta+\beta\left(3 u_{0}-2 u_{1}\right)}{6}-p_{d}-\left(\frac{b^{2}}{2}-1\right)\left(c_{0}-p_{d}\right)+\frac{\beta\left(3 u_{0}-2 u_{2}\right)}{3}+a(1-\theta) \\
\frac{d \pi_{m}^{Y}}{d w} & =b p_{d}-w-\frac{b c_{0}}{2}+\frac{a \theta}{2}+\frac{\beta\left(3 u_{0}-2 u_{1}\right)}{6} .
\end{aligned}
$$

The Hessian matrix about the supplier's decision-making is $H_{m}^{Y}=\left(\begin{array}{cr}b^{2}-2 & -b \\ -b & -1\end{array}\right)$ which satisfies $\operatorname{det}\left(H_{m}^{Y}\right)=$ $2-2 b^{2}>0$. Apparently, we can confirm that $\pi_{m}^{Y}$ is a jointly concave function of $p_{d}, w$, so there must be an optimal pricing strategy that maximizes the expected profit. We obtain the optimal pricing strategy of the supplier as follows:

$$
\begin{aligned}
w^{Y^{*}} & =\frac{b A+B}{6\left(1-b^{2}\right)} \\
p_{d}^{Y^{*}} & =\frac{A+b B}{6\left(1-b^{2}\right)}+\frac{c_{0}}{2},
\end{aligned}
$$

where $A=3 a-3 a \theta+3 \beta u_{0}-2 \beta u_{2}, B=3 a \theta+3 \beta u_{0}-2 \beta u_{1}$.

Substitute the supplier's optimal pricing into $p_{r}$ and the retailer's final optimal pricing is listed as follows:

$$
p_{r}^{Y^{*}}=\frac{3 B+2 b A-b^{2} B}{12\left(1-b^{2}\right)}+\frac{b c_{0}}{4} .
$$

Therefore, the market demands of the retailer and the supplier are respectively listed as follows:

$$
\begin{aligned}
& D_{1}^{Y^{*}}=\frac{3 b c_{0}+B}{12} \\
& D_{2}^{Y^{*}}=\frac{2 A+b B+3 b^{2} c_{0}-6 c_{0}}{12} .
\end{aligned}
$$


Accordingly, the optimal expected profit functions of the retailer and the supplier are:

$$
\begin{aligned}
& \pi_{r}^{Y^{*}}=\frac{\left(3 a \theta-2 \beta u_{1}+3 \beta u_{0}+3 b c_{0}\right)^{2}}{144} \\
& \pi_{m}^{Y^{*}}=\frac{(A-B)^{2}}{72(b+1)}-\frac{(A+B)^{2}}{72(b-1)}-\frac{B^{2}}{72}-\frac{\left(4 A+2 b B+3 b^{2} c_{0}-6 c_{0}\right) c_{0}}{24} .
\end{aligned}
$$

Based on the optimal pricing and demand expressions above, it's easy to find that there are equilibrium decisions for this game. The optimal pricing decisions are relevant with some parameters such as the operating cost of the internet channel, decay rate and the sensitivity coefficient of market demand to price of another channel. Corollary 3.1 and 3.2 can be deduced. Therefore, under certain parameters, the equilibrium is unique.

Corollary 3.1. In a dual-channel FAP supply chain, the optimal wholesale price is irrelevant with the operating cost of the internet channel; the optimal traditional channel demand function, internet price and the traditional retail price increase with the increase of the internet operating cost. The optimal internet channel demand function decreases with the increase of internet operating cost.

Corollary 3.2. There is an upper limit on the supplier's internet operating cost which is given by $C_{*}^{Y}=\frac{2 A+b B}{3(2-b)^{2}}$.

Proof. By analyzing the relationship between optimal pricing and market demand, we obtain $D_{2}^{Y^{*}}=$ $\frac{2 A+b B+3 b^{2} c_{0}-6 c_{0}}{12}>0$, so the upper limit on internet operating cost is $C_{*}^{Y}=\frac{2 A+b B}{3\left(2-b^{2}\right)}$.

According to equations (3.14) and (3.18), we obtain Corollary 3.3 as follows.

Corollary 3.3. In a dual-channel FAP supply chain, the optimal wholesale price and retail price of FAPs decrease with the increase of decay rate $u_{1}, u_{2}$. The optimal internet demand goes down as the decay rate $u_{1}, u_{2}$ goes up; the optimal traditional demand decreases as traditional channel decay rate $u_{1}$ increases, having little relevance with the decay rate $u_{2}$ of the internet channel.

According to equations (3.19) and (3.20), we obtain Corollary 3.4 as follows:

Corollary 3.4. The optimal profit of the retailer in a dual-channel FAP supply chain grows with the enlargement of the market share of traditional channel, channel price substitution coefficient and consumers' sensitivity to the product freshness. When $c_{0} \in\left(\frac{2 A+b B}{6-3 b^{2}+3 b}, C_{*}^{Y}\right)$, the optimal profit of the supplier increases as the market share of traditional channel increases; conversely, when $c_{0} \in\left(0, \frac{2 A+b B}{6-3 b^{2}+3 b}\right)$, the supplier's profit shrinks with the increase of market share.

Proof. According to equation (3.19), we obtain relationships between the retailer's profit and market share ratio, channel price substitution coefficient and consumers' sensitivity to the product freshness. In view of Corollary 3.2 and equation (3.20), the derivative of the supplier's profit to market share ratio and consumers' sensitivity to the product freshness are as follows:

$$
\frac{\mathrm{d} \pi_{m}^{Y^{*}}}{\mathrm{~d} \theta}=\frac{-a\left(2 A+b B+3 b^{2} c_{0}-3 b c_{0}-6 c_{0}\right)}{12(b+1)}
$$

when $c_{0} \in\left(\frac{2 A+b B}{6-3 b^{2}+3 b}, C_{*}^{Y}\right)$, then $2 A+b B+3 b^{2} c_{0}-3 b c_{0}-6 c_{0}<0$ and $\frac{\mathrm{d} \pi_{m}^{Y *}}{\mathrm{~d} \theta}<0$. In a similar manner, the conclusion under $c_{0} \in\left(0, \frac{2 A+b B}{6-3 b^{2}+3 b}\right)$ can be proved. 


\subsection{Comparative analysis before and after the introduction of the internet channel}

According to equations (3.6), (3.7), (3.19) and (3.20), the expected profit difference before and after the supplier's introduction of the internet channel are as follows:

$$
\begin{aligned}
\Delta \pi_{m} & =\pi_{m}^{Y^{*}}-\pi_{m}^{N^{*}}=\frac{(A-B)^{2}}{72(b+1)}-\frac{(A+B)^{2}}{72(b-1)}-\frac{B^{2}+\left(3 a-2 \beta u_{1}+3 \beta u_{0}\right)^{2}}{72}-\frac{\left(4 A+2 b B+3 b^{2} c_{0}-6 c_{0}\right) c_{0}}{24} \\
\Delta \pi_{r} & =\pi_{r}^{Y^{*}}-\pi_{r}^{N^{*}}=\frac{\left(b c_{0}+a \theta-a\right)\left(3 b c_{0}+3 a+3 a \theta-4 \beta u_{1}+6 \beta u_{0}\right)}{48}
\end{aligned}
$$

Theorem 3.5 can be drawn from equation (3.22).

Theorem 3.5. When $G_{0}<0$, and the supplier's internet operating cost is in the range $\left(0, C_{*}^{Y}\right)$, the supplier can benefit from introduction of the internet channel. When $G_{0} \geq 0$ and $2 A+b B>\sqrt{G_{0}} / \sqrt{1-b^{2}}$, the supplier is willing to introduce the internet channel when internet operating cost satisfies $c_{0} \in\left(0, c_{1}\right)$; when $c_{0} \in\left(c_{1}, C_{*}^{Y}\right)$, profit goes down with the introduction of the internet channel, therefore the supplier will not introduce the internet channel. When $G_{0} \geq 0$ and $2 A+b B \leq \sqrt{G_{0}} / \sqrt{1-b^{2}}$, with $c_{0} \in\left(0, C_{*}^{Y}\right)$, the supplier cannot gain extra profit from the internet channel, so that they will be reluctant to introduce the internet channel.

Proof. Suppose $G\left(c_{0}\right)=\frac{\left(2-b^{2}\right) c_{0}^{2}}{8}-\frac{(4 A+2 b B) c_{0}}{24}+\frac{(A-B)^{2}}{72(b+1)}-\frac{(A+B)^{2}}{72(b-1)}-\frac{B^{2}+\left(3 a-2 \beta u_{1}+3 \beta u_{0}\right)^{2}}{72}$. Obviously, $G\left(c_{0}\right)$ is a quadratic function of $c_{0}$, which is concave and reaches the minimum at $c=\frac{2 A+b B}{3\left(2-b^{2}\right)}>0$. If $G_{0}<0$, that is, the quadratic function does not generate real roots in this case, $G\left(c_{0}\right)>0$ holds within the whole domain. Whereas if $G_{0} \geq 0$, then real roots $c_{1}, c_{2}$ exist when $G\left(c_{0}\right)=0$, and if $2 A+b B>\sqrt{G_{0}} / \sqrt{1-b^{2}}$, under $c_{0} \in\left(0, c_{1}\right)$ then $G\left(c_{0}\right)>0$; while under $c_{0} \in\left(c_{1}, C_{*}^{Y}\right)$ then $G\left(c_{0}\right)<0$. If $2 A+b B \leq \sqrt{G_{0}} / \sqrt{1-b^{2}}$, then under $c_{0} \in\left(0, C_{*}^{Y}\right), G\left(c_{0}\right)<0$. Among them,

$$
\begin{aligned}
c_{1}= & \frac{2 A+b B-\sqrt{G_{0}} / 12 \sqrt{2\left(1-b^{2}\right)}}{(6-3 b)} ; \quad c_{2}=\frac{2 A+b B+\sqrt{G_{0}} / 12 \sqrt{2\left(1-b^{2}\right)}}{\left(6-3 b^{2}\right)} \geq C_{*}^{Y} ; \\
G_{0}= & \left(9 a^{2} b^{2}\left(b^{2}-4 \theta^{2}+8 \theta-7\right)+36 a^{2} b \theta(\theta-1)-18 a^{2}\left(\theta^{2}-1\right)\right. \\
& \left.+6 a \beta\left(2 u_{1}-3 u_{0}\right)(b+1)\left(4 b+2 \theta-2 b \theta+b^{2}-b^{3}-2\right)-b \beta^{2}\left(2 u_{2}-3 u_{0}\right)^{2}\left(-b^{3}+5 b+4\right)\right) .
\end{aligned}
$$

Theorem 3.6 can be drawn from equation (3.23).

Theorem 3.6. After the supplier introduces the internet channel, whether the profit of traditional retailer will be damaged depends on the supplier's internet operating cost. If $c_{0} \in\left(\min \left(\frac{a(1-\theta)}{b}, C_{*}^{Y}\right), C_{*}^{Y}\right)$, then the retailer will benefit from the introduction of the internet channel; whereas if $c_{0} \in\left(0, \min \left(\frac{a(1-\theta)}{b}, C_{*}^{Y}\right)\right)$, then the retailer will be hit by the internet channel.

Proof. The profit difference of the retailer before and after the introduction of the internet channel is given by

$$
\Delta \pi_{r}=\frac{\left(b c_{0}+a \theta-a\right)\left(3 b c_{0}+3 a+3 a \theta-4 \beta u_{1}+6 \beta u_{0}\right)}{48} .
$$

In view of previous assumptions, we obtain $\left(3 b c_{0}+3 a+3 a \theta-4 \beta u_{1}+6 \beta u_{0}\right)>0$. Thus, the sign before $\left(b c_{0}+a \theta-a\right)$ determines the trend of the retailer's profit. Additionally, internet operating cost satisfies $c_{0} \in\left(0, C_{*}^{Y}\right)$, so we can draw the following conclusions: when $c_{0} \in\left(\min \left(\frac{a(1-\theta)}{b}, C_{*}^{Y}\right), C_{*}^{Y}\right)$, then $\Delta \pi_{r}>0$, which means the retailer will benefit from the introduction of the internet channel; whereas when $c_{0} \in\left(0, \min \left(\frac{a(1-\theta)}{b}, C_{*}^{Y}\right)\right)$, then $\Delta \pi_{r}<0$, which means the retailer's profit will be damaged by internet channel. 
Corollary 3.7 can be derived from Theorems 3.5 and 3.6.

Corollary 3.7. When internet operating cost of FAPs is under certain conditions, the introduction of the internet channel could be a "win-win" situation for both sides of the supply chain. According to theorems, if both the supplier and the retailer can obtain profit from the introduction of the internet channel, then one of the following conditions must be met:

(1) when $\frac{a(1-\theta)}{b}<C_{*}^{Y}$ and $G_{0}<0$, internet operating cost satisfies $c_{0} \in\left(\frac{a(1-\theta)}{b}, C_{*}^{Y}\right)$;

(2) when $\frac{a(1-\theta)}{b}<c_{1}<C_{*}^{Y}, G_{0} \geq 0$ and $2 A+b B>\sqrt{G_{0}} / \sqrt{1-b^{2}}$, internet operating cost satisfies $c_{0} \in$ $\left(\frac{a(1-\theta)}{b}, c_{1}\right)$.

There are a lot of parameters involved in the comparative analysis of optimal pricing and demand before and after the introduction of channel, which will be further discussed in Section 5 Case Analysis.

\section{A Win-Win CONTRACT FOR THE DUAL-CHANNEL FAP SUPPly CHAin}

From the previous analysis, when the supplier's internet operating cost meets certain conditions, the introduction of the internet channel will have three types of results: (1) profits grow for both the supplier and the retailer; (2) the retailer' profit drops while the supplier's profit rises; (3) profits shrink for both the supplier and the retailer. According to the rational person hypothesis, only when both sides' profits are improved can the supply chain be in a relatively stable and ideal state of cooperation.

We are going to apply the revenue-sharing contract to solve the problem of the retailer' profit reduction caused by the introduction of the internet channel. In order to promote close cooperation among fresh enterprises, the supplier will surrender a part of profit to the retailer, denoted by $\psi(\psi \in(0,1))$, while they keep the rest $1-\psi$.

After the introduction of internet channel and under the revenue-sharing contract, the retailer's profit function is given by:

$$
\begin{aligned}
\pi_{r}^{\circ}= & \left(p_{r}-w\right) \frac{1}{T} \int_{0}^{T}\left(\theta a-p_{r}+b p_{d}+\beta\left(u_{0}-u_{1}\left(\frac{t}{T}\right)^{1 / 2}\right)\right) \mathrm{d} t \\
& +\psi p_{d} \frac{1}{T} \int_{0}^{T}\left[(1-\theta) a-p_{d}+b p_{r}+\beta\left(u_{0}-u_{2}\left(\frac{t}{T}\right)^{1 / 2}\right)\right] \mathrm{d} t
\end{aligned}
$$

and the supplier's expected profit function is given by:

$$
\begin{aligned}
\pi_{m}^{\circ}= & w \frac{1}{T} \int_{0}^{T}\left(\theta a-p_{r}+b p_{d}+\beta\left(u_{0}-u_{1}\left(\frac{t}{T}\right)^{1 / 2}\right)\right) \mathrm{d} t \\
& +\left((1-\psi) p_{d}-c_{0}\right) \frac{1}{T} \int_{0}^{T}\left[(1-\theta) a-p_{d}+b p_{r}+\beta\left(u_{0}-u_{2}\left(\frac{t}{T}\right)^{1 / 2}\right)\right] \mathrm{d} t .
\end{aligned}
$$

Meanwhile, in order to determine the range of revenue-sharing ratio, the following constraints must be met: the expected profits of the retailer and the supplier after introducing internet channel are greater than that of traditional single-channel situation. Therefore, the constraints of the optimization problem are as follows: $\pi_{r}^{\circ} \geq \pi_{r}^{N^{*}}, \pi_{m}^{\circ} \geq \pi_{m}^{N^{*}}$. 
The pricing decisions after the introduction of revenue-sharing contract are as follows:

$$
\begin{aligned}
p_{d}^{\circ *} & =\frac{c_{0}}{2(1-\psi)}+\frac{A+b B}{6(1-b)(b+1)}, \\
w^{\circ *} & =\frac{B-b^{2} \psi B+A b-A \psi}{6(1-b)(b+1)}, \\
p_{r}^{\circ *} & =\frac{b c_{0}(1+\psi)}{4(1-\psi)}+\frac{3 B+2 b A-b^{2} B}{12(1-b)(b+1)} .
\end{aligned}
$$

By substituting the optimal pricing into the demand function, we obtain the corresponding optimal demand as follows:

$$
\begin{aligned}
D_{1}^{\circ *} & =\frac{9 b c_{0}+B}{12}-\frac{b c_{0}}{2(1-\psi)}, \\
D_{2}^{\circ *} & =\frac{2 A+b B-6 c_{0}-3 b^{2} c_{0}}{12}+\frac{b^{2} c_{0}}{2(1-\psi)} .
\end{aligned}
$$

According to equations (4.3)-(4.5), we can get the optimal profit functions of supply chain members. Because of the complexity of expressions, they will not be demonstrated here. Likewise, the range of revenue-sharing ratio $\psi$ derived from the constraint will be displayed in Section 5 Case Analysis. In addition, Corollaries 4.1 and 4.2 are obtained based on equations (4.3)-(4.7).

Corollary 4.1. With the introduction of revenue-sharing contract, the pricing relationship between internet and traditional channel are as follows: $p_{d}^{\circ *}>p_{d}^{Y^{*}}, p_{r}^{\circ *}>p_{r}^{Y^{*}}, w^{\circ *}<w^{Y^{*}}$. The retail price of FAPs is higher than that before revenue-sharing contract was introduced; whereas the wholesale price after the introduction of revenue-sharing contract is lower than before.

Proof. Based on equations (3.15) and (4.3), we obtain the internet price difference with and without the revenuesharing contract as $p_{d}^{\circ *}-p_{d}^{Y^{*}}=\frac{c_{0}}{2(1-\psi)}-\frac{c_{0}}{2}>0$. Based on equations (3.16) and (4.5), the traditional price difference before and after the introduction of the contract is $p_{r}^{\circ *}-p_{r}^{Y^{*}}=\frac{b c_{0}(1+\psi)}{4(1-\psi)}-\frac{b c_{0}}{4}>0$. Besides, according to equations (3.14) and (4.4), the wholesale price difference before and after the contract was introduced is $w^{\circ *}-w^{Y^{*}}=\frac{-b^{2} \psi B-A \psi}{6(1-b)(b+1)}<0$.

Corollary 4.2. After the revenue-sharing contract is introduced as a compensation mechanism for introducing internet channel, the retailer' traditional demand decreases compared with that before the introduction of the contract, and decreases with the increase of revenue-sharing ratios. The supplier's internet demand increases after the introduction of the contract and increases with the increase of revenue-sharing ratio.

Proof. Based on equations (3.17) and (4.6), we obtain $D_{1}^{\circ *}-D_{1}^{Y^{*}}=-\frac{b c_{0} \psi}{2(1-\psi)}<0$, that is, traditional demand decreases after revenue sharing; whereas from equations (3.18) and (4.7), we get $D_{2}^{\circ *}-D_{2}^{Y^{*}}=\frac{b^{2} c_{0} \psi}{2(1-\psi)}>0$, which means internet demand grows after revenue sharing.

\section{CASE ANALYSis}

To present previous conclusions more clearly, this section will further demonstrate and verify these conclusions through numerical examples.

According to the literature in the field of fresh supply chain and dual-channel [19], the relevant parameters are set as follows: market scale $a=100$, price substitution coefficient $b=0.8$, traditional market share proportion $\theta=0.5$, consumers' sensitivity to the product freshness $\beta=10$, initial freshness level of FAPs $u_{0}=0.95$, and deterioration rate in two channels $u_{1}=0.05, u_{2}=0.08$, respectively. 


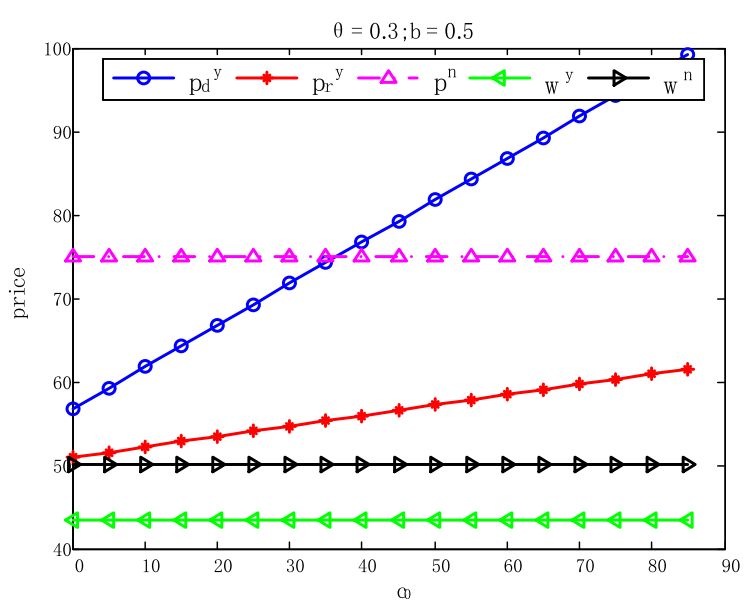

(a)

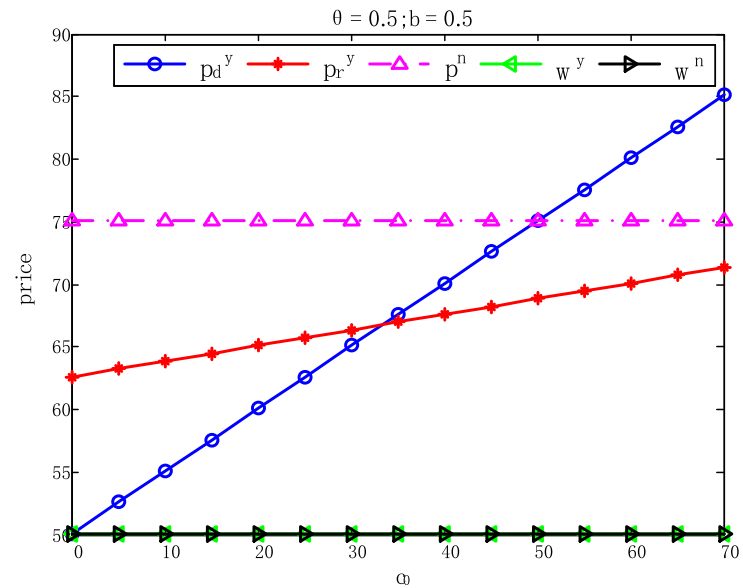

(b)

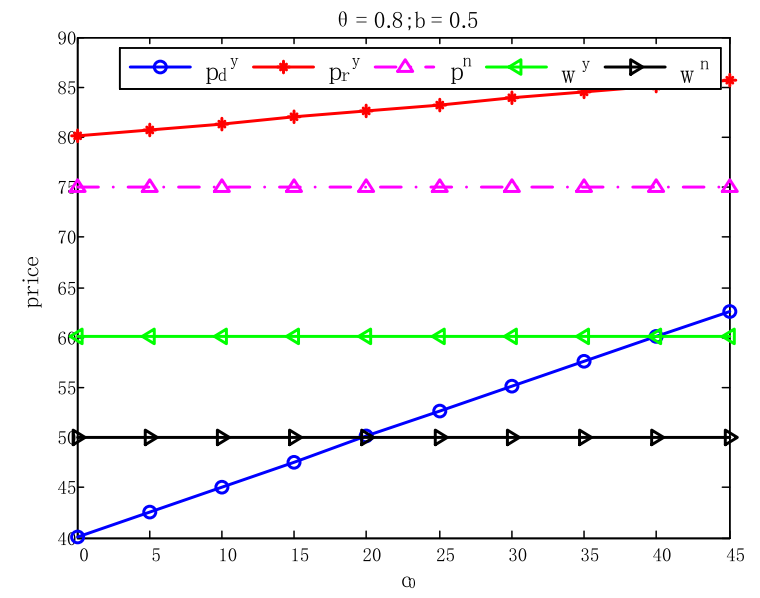

(c)

Figure 2. The impact of internet operating cost on prices under different market share.

\subsection{Analysis of the impact of internet operating cost on supply chain prices}

We assume internet operating cost $c_{0} \in\left[0, C_{*}^{Y}\right]$ and the market share and price substitution coefficient are in different values respectively when other parameters remain constant.

(1) The impact of internet operating cost on supply chain prices under various market share.

Assume that market share $\theta=0.3,0.5$, and 0.8 , respectively, thus, the relationships between internet operating cost and prices under different market share of traditional channel are shown in Figure 2.

According to Figure 2, the wholesale price and traditional single-channel retail price before and after the introduction of internet channel are not affected by the change of internet operating cost. Moreover, the retail price after the introduction of internet channel increases along with internet operating cost, and the internet price grows faster than the traditional price. Meanwhile, internet operating cost does not affect the cultivation and production of FAPs, so it doesn't affect the wholesale price. However, internet operating cost directly determines the supplier's internet pricing and therefore influences the retailer' pricing decision, which finally affects the retailer's pricing strategy of traditional channel indirectly. 
As market share of traditional channel increases, the wholesale price after the introduction of internet channel increases, and the relationship with the wholesale price of single channel gradually changes from "less than" to "equal to", and finally to "greater than". Furthermore, with the increase of traditional channel market share, internet price diminishes gradually after the introduction of internet channel, while traditional retail price increases. Similar to the tendency of wholesale price before and after the introduction of internet channel, regardless of internet operating cost, internet price will ultimately go down below traditional single-channel retail price with the enlargement of traditional market share; the traditional retail price in dual channel is completely lower than the retail price in single channel.

This kind of situation is in line with real life, where there is no competition between the supplier and the retailer and the optimal price will not be influenced by traditional market share in traditional single-channel supply chain. When internet channel is introduced, price competition emerges between internet and traditional channels. As traditional market share expands, most of the supplier's profit comes from traditional channel. To generate more profits, the supplier will lift the wholesale price of FAPs, and to cope with price competition and market share disadvantage, a low-price strategy that can attract more internet channel customers will be adopted by the supplier. For the retailer, it will take advantage of its large market share and moderately improve traditional retail price to increase the profit.

(2) The impact of internet operating cost on supply chain prices under various price substitution coefficients.

Suppose that price substitution coefficient $b=0.3,0.5$, and 0.8 respectively, we obtain the relations between internet operating cost and prices under different price substitution coefficients, as shown in Figure 3.

With the increase of channel price substitution coefficient, the wholesale price after the introduction of internet channel rises and gradually surpasses the traditional single-channel wholesale price. Apart from this, the retail price in dual channel increases along with the price substitution coefficient and is ultimately greater than that in traditional single channel. In the dual channel, however, traditional retail price of FAPs is higher than internet price at first, and then gradually declines to the same level, and eventually ends up being less than internet price. Thus, when market share is fixed, internet and traditional prices depend on not only the price substitution coefficient but also internet operating cost. That is because with the increase of price substitution coefficient, internet and traditional prices will have a stronger impact on the other channel demand. When other factors remain unchanged, the demand for FAPs enlarges, in which case the supplier will improve the profit by raising wholesale price and adjust internet price according to the retailer's price rising.

Furthermore, it also indicates that as the price substitution coefficient grows, the upper limit of internet operating cost that equalizes internet and traditional retail prices is also gradually increasing. That is because the growth in price substitution coefficient increases internet and traditional retail prices simultaneously, and increases the influence coefficient of internet operating cost on traditional retail price. In other words, the traditional price grows faster than that of the internet, which causes the rise in price substitution coefficient and elevates the upper limit of internet operating cost that equalizes internet and traditional retail prices.

\subsection{Analysis of the impact of internet operating cost on market demand}

(1) The impact of internet operating cost on market demand under various market shares.

Assume that market share $\theta=0.3,0.5$, and 0.8 , respectively, we obtain relations between internet operating cost and prices under various traditional market shares, as shown in Figure 4.

According to Figure 4, as internet operating cost augments, internet channel demand declines and traditional channel demand increases, while traditional single-channel demand isn't affected by it. This is because the increase in internet operating cost raises the supplier's internet price, which indirectly improves traditional retail price. However, the impact of internet operating cost on internet price is more significant than that on traditional retail price. To sum up, with the increase of internet operating cost, traditional channel demand grows while internet channel demand shrinks. 


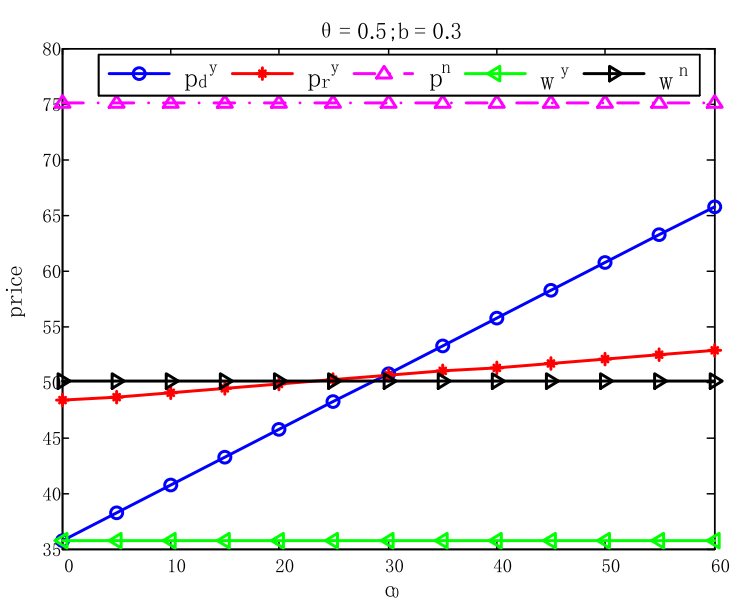

(a)

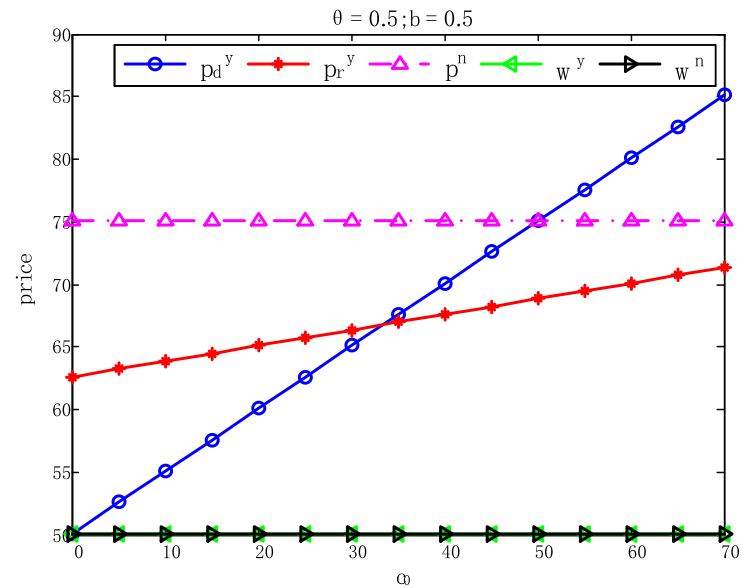

(b)

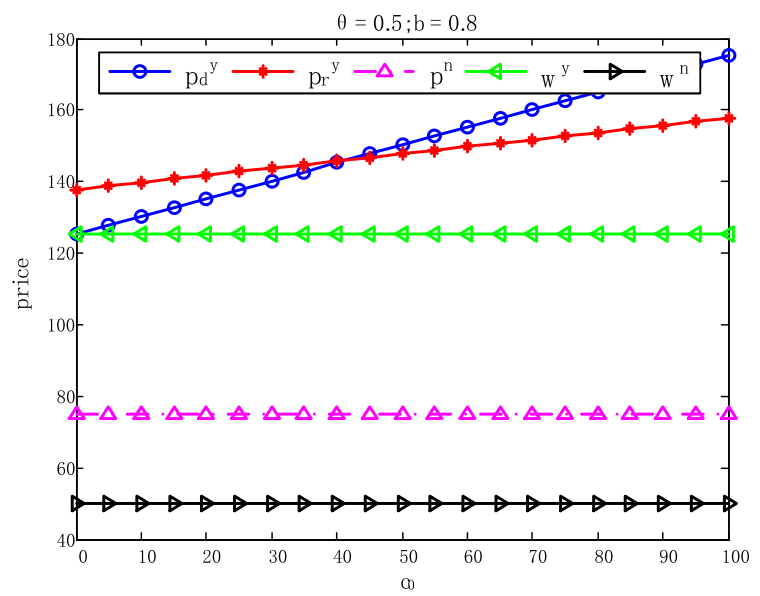

(c)

FiguRE 3. The impact of internet operating cost on prices under different price substitution coefficients.

In addition, by comparing market demand under three different market shares, we find out that as traditional channel market share expands, the gross demand in the case of dual channel rises as well, and will finally be always greater than that of traditional single channel. Both internet and traditional channel demands enlarge as market share $\theta$ expands. That is because as traditional channel market share gradually grows, the supplier can only attract customers by improving wholesale price and reducing internet price so as to maximize the internet market competitiveness.

(2) The impact of internet operating cost on market demand under various price substitution coefficients.

Suppose that price substitution coefficient $b=0.3,0.5$, and 0.8 , respectively, we obtain the relations between internet operating cost and traditional channel market demand under various price substitution coefficients, as shown in Figure 5.

Figure 5 demonstrates market demand under three different price substitution coefficients. With the increase of price substitution coefficient, in the dual-channel supply chain, the total demand increases, and the demand of internet and traditional channels also increases. As the price substitution coefficient increases, the growth rate 


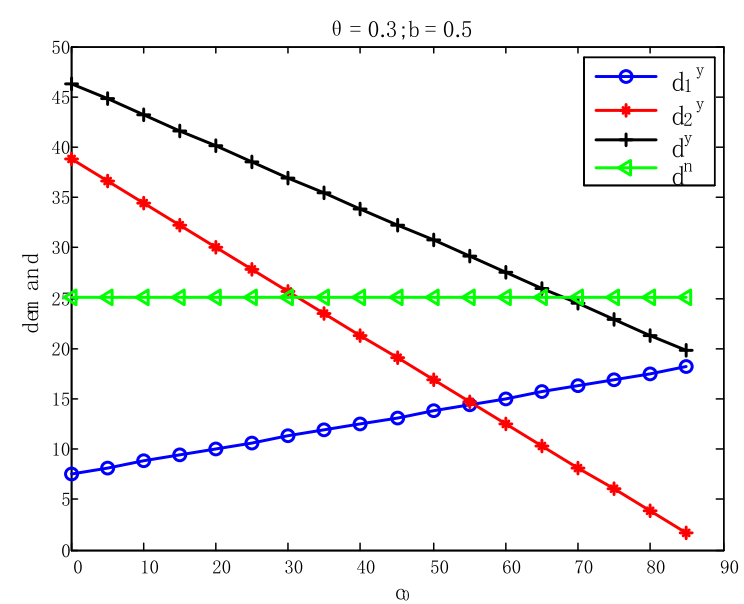

(a)

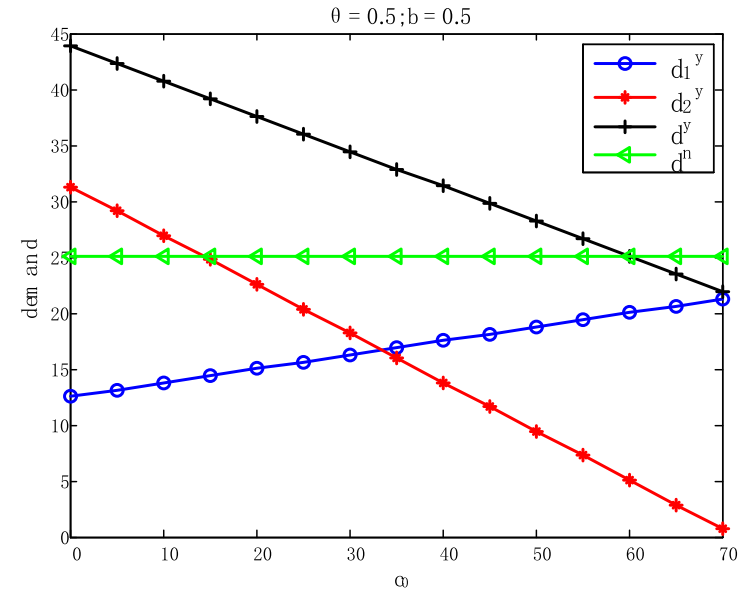

(b)

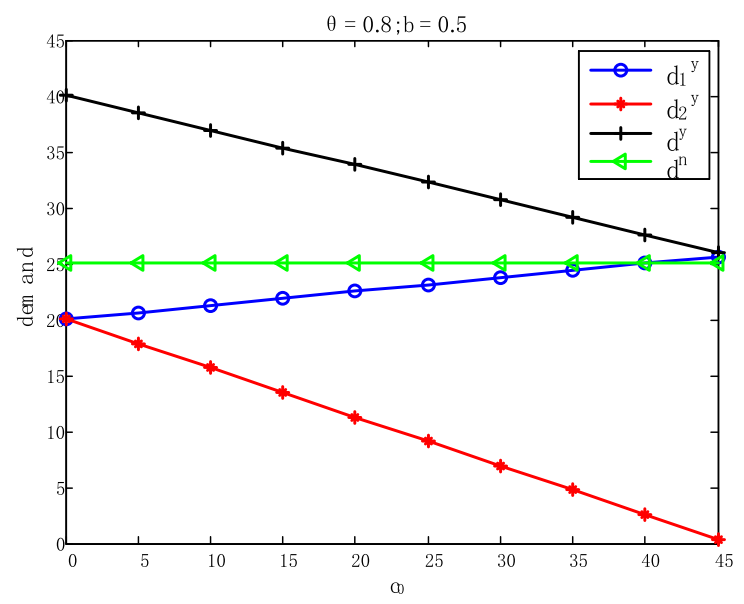

(c)

FIGURE 4. The impact of internet operating cost on market demand under different market shares.

of internet demand increases while the reduction rate diminishes. That is because when the price substitution coefficient is larger, the impact between channel prices is stronger and the retail price of FAPs is gradually increased. In fine, price substitution coefficient is becoming increasingly influential in demand.

\subsection{Analysis of the impact of internet operating cost on supply chain members' profits}

In this section, we will analyze the impact of internet operating cost on supply chain members' profits before and after the introduction of internet channel to determine whether the supplier should introduce internet channel or not.

(1) The impact of internet operating cost on profits under various traditional channel market shares.

As can be seen from Figure 6a, when traditional channel market share is limited, i.e., $\theta=0.3$, the critical value range of internet operating cost $c_{0} \in(40,50)$, displayed by the black dotted line in the figure. If internet operating cost is less than $c_{0}$, the supplier will benefit from the introduction of internet channel while the retailer will suffer from profit loss; whereas if internet operating cost is greater than $c_{0}$, then both the supplier and the retailer will be hit by the introduction of internet channel. 


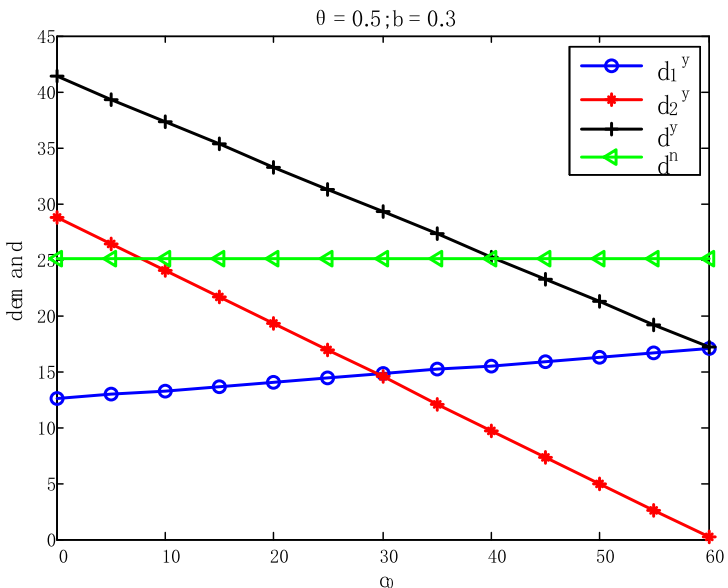

(a)

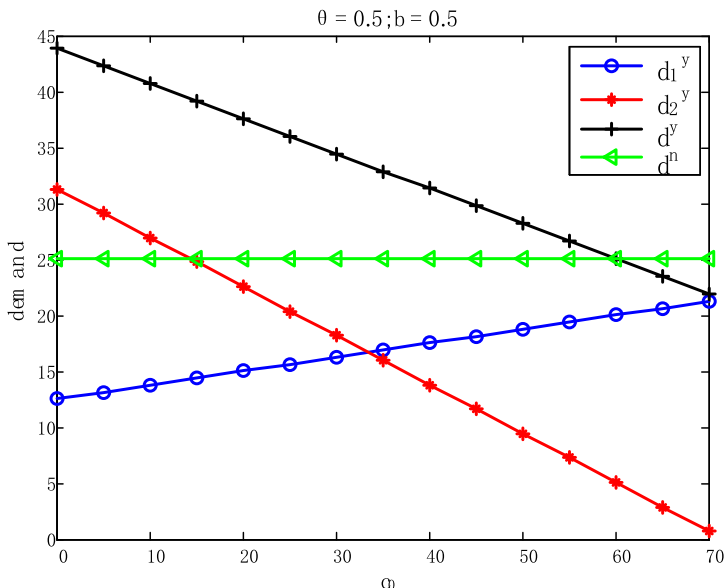

(b)

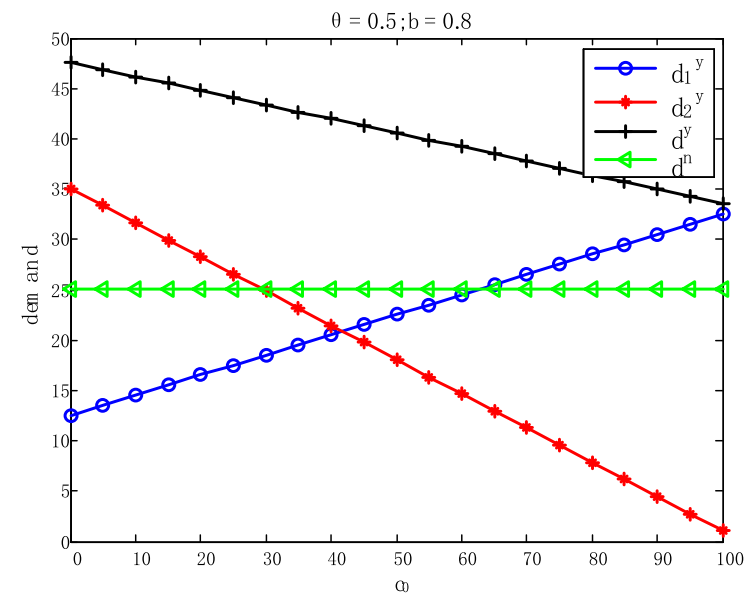

(c)

FiguRE 5. The impact of internet operating cost on market demand under various price substitution coefficients.

As shown in Figure 6b, when traditional channel market share is of medium scale, i.e., $\theta=0.5$, the critical value range of internet operating cost $c_{0} \in(40,50)$, displayed by the black dotted line in the figure. The conclusion here is consistent with the case when $\theta=0.3$.

Figures $6 \mathrm{c}$ and $6 \mathrm{~d}$ illustrate that when traditional channel market share is substantial, i.e., $\theta=0.8,0.9$, the critical value range of internet operating cost is written respectively as $c_{0} \in(36,42)$ and $c_{0} \in(18,22)$, displayed by the pink dotted lines in the figures. If internet operating cost is less than $c_{0}$, only the supplier will gain from the introduction of internet channel; whereas if internet operating cost is greater than $c_{0}$, then both the supplier and the retailer will benefit from the introduction of internet channel, which is a win-win situation.

All in all, after the introduction of internet channel, the supplier's profit declines with the increase of internet operating cost. However, with the increase of the traditional channel market share, the decline rate of the supplier's profit is weakened, while the growth rate of the retailer's profit is gradually accelerated. In the end, the profits of supply chain members will all be higher than that of traditional single-channel, and thus a win-win situation appears. 


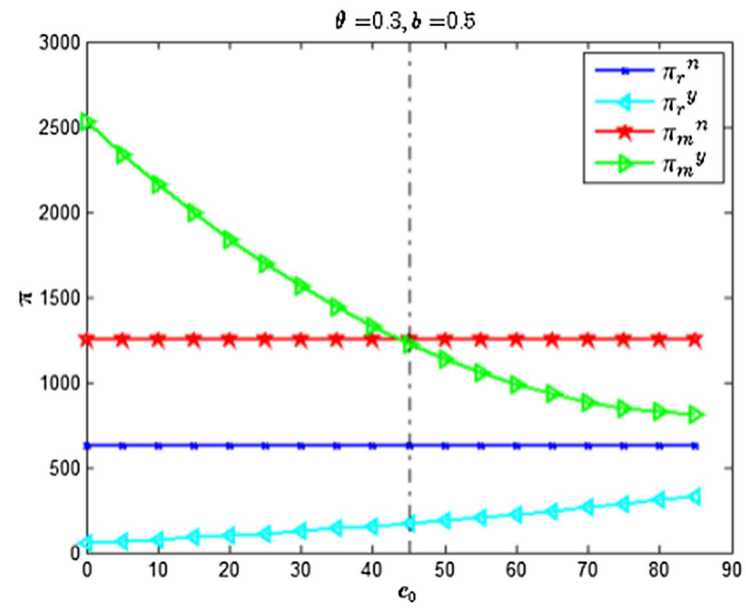

(a)

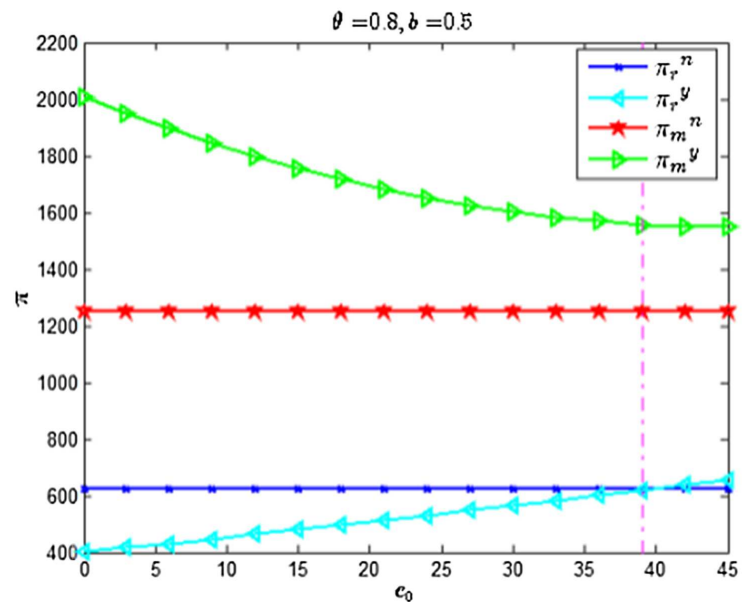

(c)

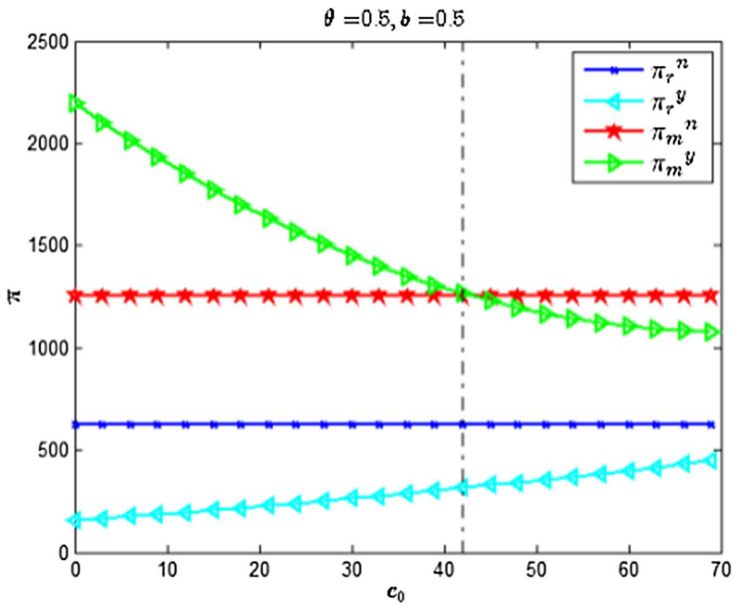

(b)

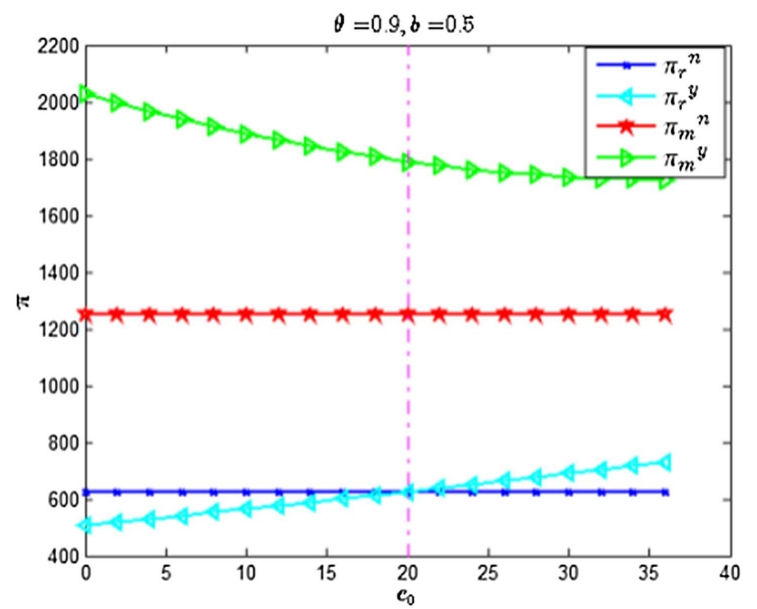

(d)

FiguRE 6 . The impact of internet operating cost on profits under different market share.

Furthermore, as traditional channel market share becomes larger, the range of internet operating cost within which the supplier is willing to introduce internet channel, and its critical value increases to its upper limit. However, the threshold value of internet operating cost that can benefit the retailer gradually decreases. In other words, with the enlargement of traditional channel market share, it is easier to achieve the win-win situation. This is because the larger the traditional market share, the lower the acceptance of internet channel by the supplier, so the lower internet operating cost. Here, the utility function of the internet channel is always greater than zero. When traditional market share accounts for a huge part, the retailer's optimal profit grows larger and its growth rate increases with market expansion, in which case despite the high internet operating cost a win-win supply chain can still be achieved.

(2) The impact of internet operating cost on profits under various price substitution coefficients.

According to Figure 7, without the introduction of internet channel, i.e., in the single-channel supply chain, profits of the supplier and the retailer are unaffected by internet operating cost. Once internet channel is 


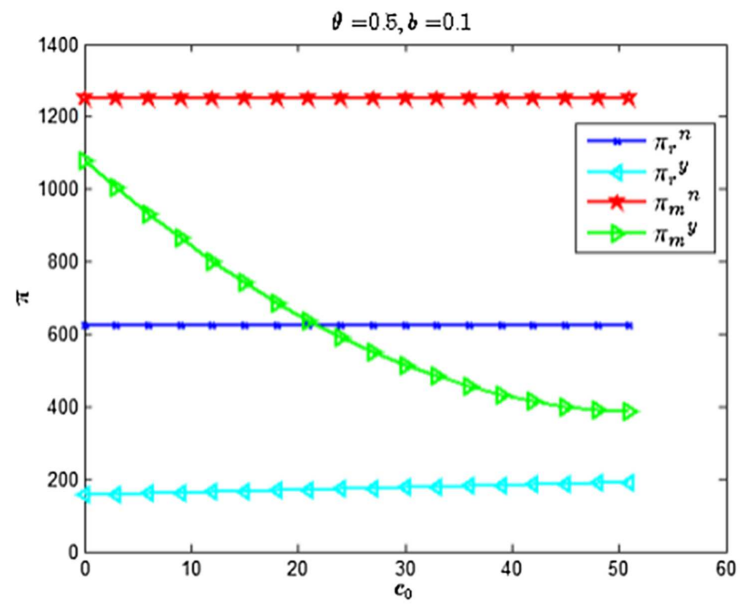

(a)

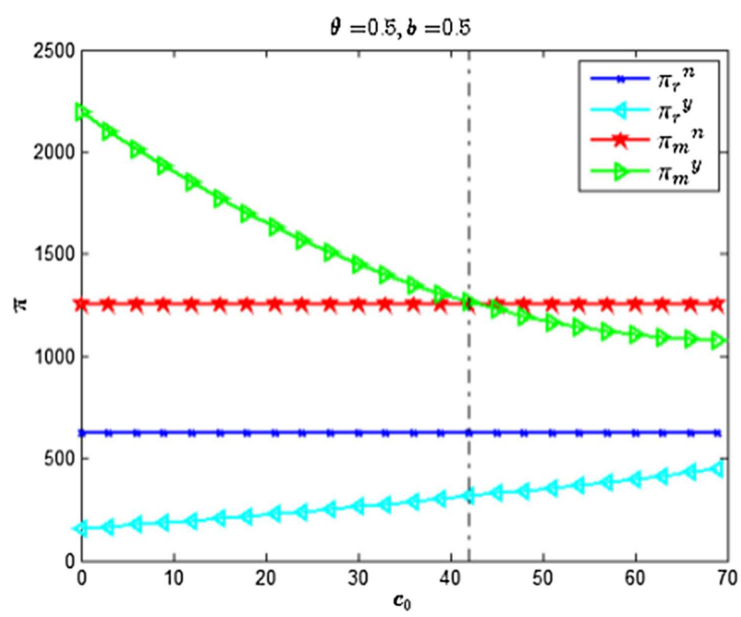

(c)

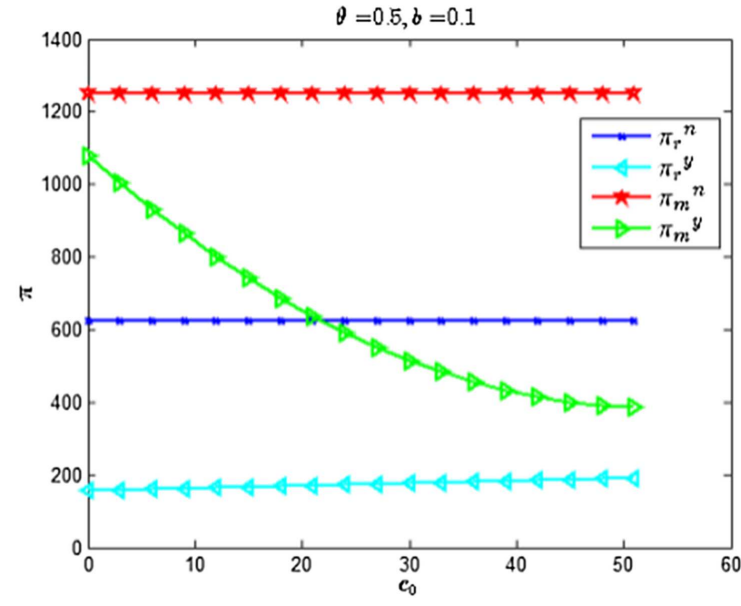

(b)

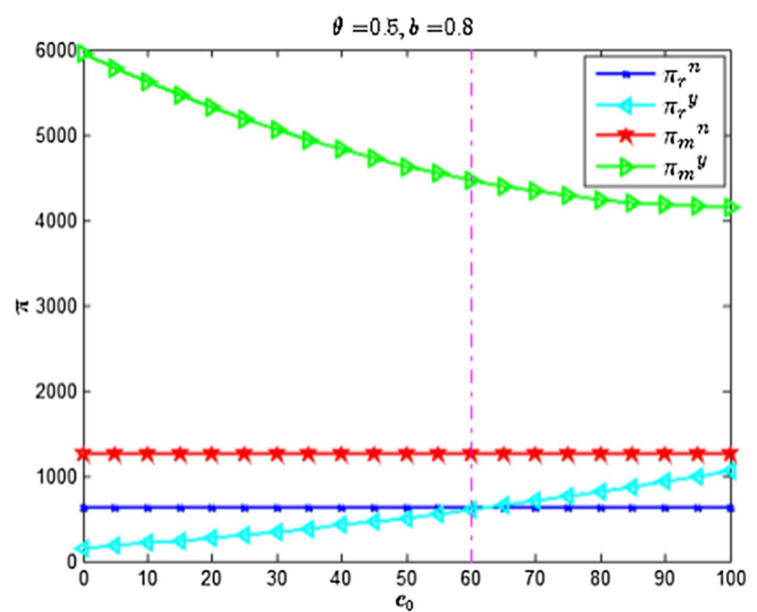

(d)

FiguRE 7. The impact of internet operating cost on profits under different price substitution coefficients.

introduced, the optimal profit of the retailer grows while the supplier's profit shrinks as internet operating cost increases.

As described in Figure 7a, when the price substitution coefficient is very small, i.e., $b=0.1$, whatever internet operating cost is, neither the retailer nor the supplier can benefit from the introduction of internet channel.

Figure $7 \mathrm{~b}$ shows that when the price substitution coefficient is relatively small, i.e., $b=0.3$, the critical value range of internet operating cost $c_{0} \in(6,10)$, displayed by the black dotted line in the figure. If internet operating cost is below $c_{0}$, then the supplier will benefit from internet channel while the retailer's profit gets hurt; whereas if internet operating cost is above $c_{0}$, both the supplier and the retailer are going to suffer profit loss due to the introduction of internet channel.

In Figure 7c, when the price substitution coefficient is of moderate value, i.e., $b=0.5$, the critical value range of internet operating cost $c_{0} \in(40,50)$, displayed by the black dotted line in the figure. The conclusion here is consistent with the case when $b=0.3$. 


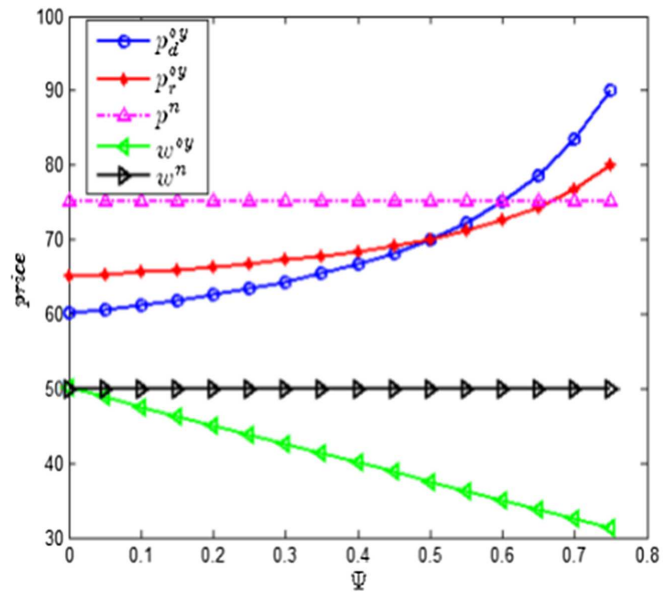

(a)

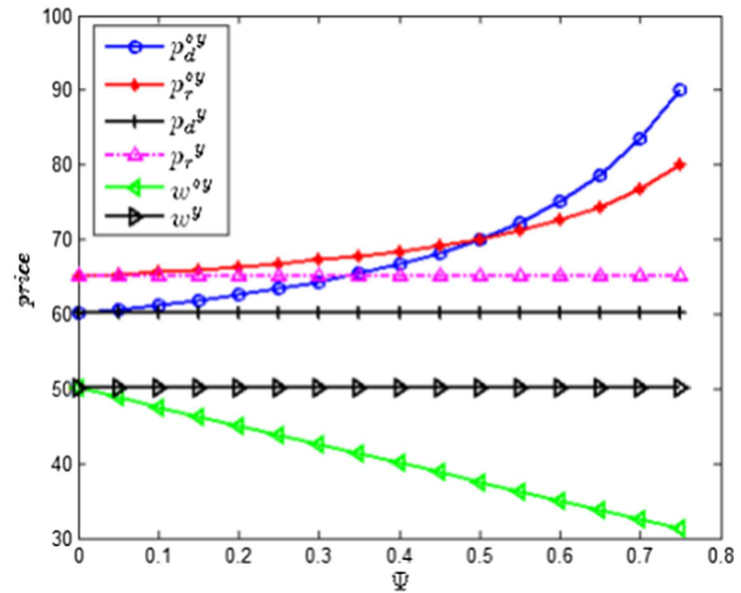

(b)

FiguRE 8. The impact of revenue-sharing ratio on prices.

As shown in Figure $7 \mathrm{~d}$, when the price substitution coefficient is significant, i.e., $b=0.8$, the critical value range of internet operating cost $c_{0} \in(55,65)$, displayed by the pink dotted line in the figure. If internet operating cost is below $c_{0}$, only the supplier will profit from the introduction of internet channel; whereas if internet operating cost is above $c_{0}$, then both the supplier and the retailer will gain from the introduction of internet channel, in which case a win-win situation is achieved.

In summary, after the introduction of internet channel, the supplier's profit decreases with the increase of internet operating cost increases, but increases with the increase of price substitution coefficient. The growth rate of the retailer's profit accelerates gradually. At last, profits of supply chain members all exceed that of traditional single channel, and thus forming a win-win situation.

According to our analysis, when other parameters are fixed, the influence of internet channel on the profits of the supplier and the retailer not only rely on internet operating cost but also price substitution coefficient. When traditional market share is given, with a small price substitution coefficient, that is, the price between channels has little influence on demand, although the introduction of internet channel enlarges market demand it also reduces retail price, which in the end does not result in better profits for the supplier and the retailer. With the increase of price substitution coefficient, competition between channels intensifies, which plays an increasingly important role in promoting demand. Under these circumstances, the supplier will make a profit by raising wholesale price moderately and improve internet retail price in response to the retailer's price hike. Ultimately, with the increase of demand, the price of agricultural products is also rising, in which case both sides of the supply chain can obtain more profits within a specific cost range.

\subsection{Effect analysis of introducing revenue-sharing contract}

(1) The impact of revenue-sharing contract on prices.

After the introduction of revenue-sharing contract, the optimal pricing strategies of the supplier and the retailer are influenced by the revenue-sharing ratio. Figure 8 a reveals that retail price after the contract is introduced is higher than that before the introduction of the contract, and the price increases with the increase of revenue-sharing ratio, which results in internet price larger than traditional retail price. However, with the increase of revenue-sharing ratio, the wholesale price of FAPs will decrease and will eventually be lower than the wholesale price before the introduction of the contract. As shown in Figure 8b, when the revenue-sharing ratio is relatively small, the retail price after the contract is introduced is lower than that before the contract 


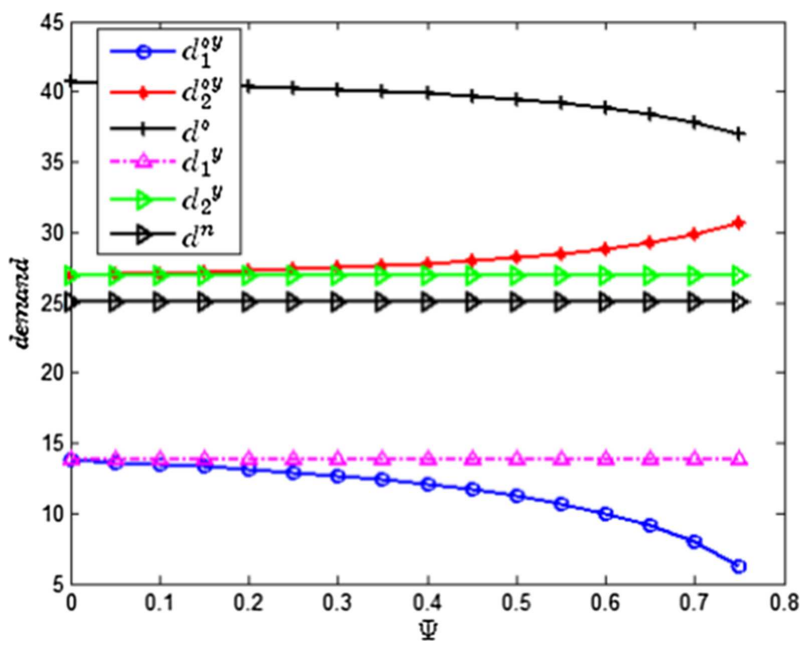

FIGURE 9. The impact of revenue-sharing ratio on demand.

is introduced; whereas when the revenue-sharing ratio is large enough, the price of FAPs will exceed the price before the introduction of internet channel. Moreover, since the contract is introduced, with the increase of revenue-sharing ratio the wholesale price decreases and will be lower than the price before the introduction of the contract. This is because after the contract is introduced, the supplier will formulate pricing strategy under the conditions of internet channel and revenue sharing. Although the development of internet channel broadens the source of income for the supplier, the existence of revenue-sharing contract weakens its profit. Therefore, as revenue-sharing ratio increases, the supplier will compete for internet channel profit by raising internet retail price and ensure the retailer's profit by reducing wholesale price, thus slowing down the price growth of traditional channel.

(2) The impact of revenue-sharing contract on demand.

After the introduction of revenue-sharing contract, the optimal demand function is affected by the revenuesharing ratio. As shown in Figure 9, the demand of internet channel after the contract is introduced is higher than that without a contract, and it increases with the increase of revenue-sharing ratio. On the contrary, the optimal demand of traditional channel decreases with the increase of revenue-sharing ratio, and is always is always lower than the optimal demand before the contract is introduced. That is because with the increase of revenue-sharing ratio, internet and traditional prices are also increasing, but the impact of price rise on the demand of two channels is different, which results in the increase of internet demand and the decrease of traditional demand. Furthermore, we note that after the introduction of the contract, with the increase of revenue-sharing ratio, the total demand gradually shrinks, but still exceeds the demand before the contract is introduced.

(3) The impact of revenue-sharing contract on profits.

The relation among profit functions, internet operating cost and revenue-sharing ratio before and after the introduction of the contract is shown in Figure 10, where the light blue surface represents the profits of supply chain members under traditional channel, while the color surface describes the profits of supply chain members after the introduction of internet channel and revenue-sharing contract. For the supplier, after the introduction of the revenue-sharing contract, within a certain range of internet operating cost, its income falls as revenue-sharing ratio climbs. When the revenue-sharing ratio increases, the supplier's profit will be less than that before the introduction of internet channel. For the retailer, after the introduction of the revenue-sharing contract, as internet 


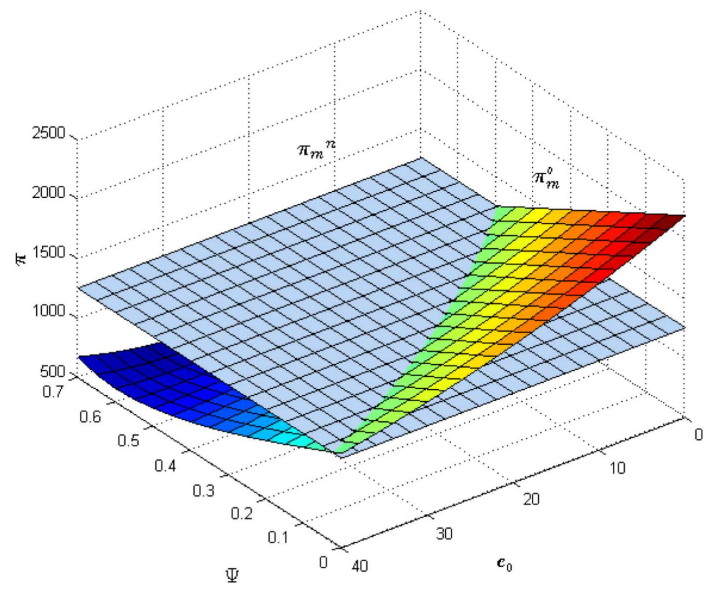

(a)

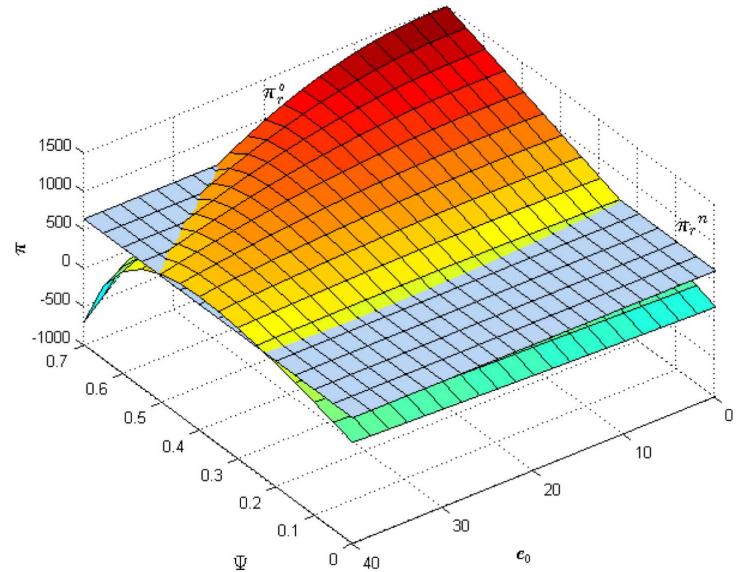

(b)

FigURE 10. The impact of revenue-sharing ratio and internet operating cost on profits.

operating cost keeps growing, the retailer's revenue changes from synchronous growth of revenue-sharing ratio to the first increase and then decrease. When the revenue-sharing ratio is within a certain range, the retailer's profit is improved compared with that before the introduction of internet channel. When internet operating cost is large enough, the retailer's profit drops sharply, and the supplier's profit also shrinks. At this point, no matter how much compensation the supplier is willing to provide, the retailer's profit will keep on reducing owing to the introduction of internet channel, which impedes the formation of a win-win situation. Overall, when revenuesharing ratio and internet operating cost satisfy $\Psi \geq 0.43$ and $0 \leq c_{0} \leq \sqrt{\frac{2.34 \psi^{2}+1.25 \psi+7.39}{8.43 \psi^{3}+4.62 \psi^{2}+5.72 \psi+9.05}}+8.64$, the profits of both the retailer and the supplier will be improved. The introduction of revenue-sharing contract is a king of compensation to the retailer's traditional market. Appropriate contract parameters can improve profits for both the supplier and the retailer, and realize Pareto Improvement of supply chain members' profits

\section{Conclusions}

This paper investigates a FAP supply chain composed of one supplier and one retailer. Taking internet operating cost of the supplier into account, we consider pricing strategies of the whole dual-channel supply chain and the impact of internet operating cost on members' decision-making after the supplier introduces internet channel. We also pay attention to quality loss of FAPs and build up channel demand functions with freshness as a factor. The relation between internet operating cost and whether the supplier introduces internet channel is studied as well. Through the comparative analysis of our model before and after the introduction of internet channel, we derive constraints that internet operating cost and other relevant parameters should meet if upstream fresh companies hope to introduce internet channel. As the conclusion indicates, when parameters like internet operating cost are under different conditions, the introduction of internet channel could lead to a winwin situation, or a one-sided triumph, or even an all-lose scenario. After the introduction of internet channel, if the retailer suffers from profit loss, then it will make the supply chain unstable, which is not conducive to the long-term corporation between fresh enterprises. Therefore, this paper introduces the revenue-sharing contract to achieve Pareto Improvement between the supplier and the retailer, and the result proves that the appropriate parameters can provide profit compensation for the retailer, thus forming a "win-win" cooperation situation. 
Acknowledgements. This work was supported by National Natural Science Foundation of China (71871098), Humanities and Social Sciences Research Planning Fund Project of the Ministry of Education (18YJA630127), and Soft Science Research Project of Guangdong Province (2019A101002119).

\section{REFERENCES}

[1] H. Albert, Y.X. Long and N. Javad, Quality in supply chain encroachment. Manuf. Serv. Oper. Manage. 18 (2015) $280-298$.

[2] V. Abhishek, K. Jerath and J.Z. Zhang, Agency selling or reselling? Channel structures in electronic retailing. Manage. Sci. 8 (2016) 2259-2280.

[3] W. Cai and J.Y. Chen, Channel management and product design with consumers' probabilistic choices. Int. J. Prod. Res. 55 (2017) 904-923.

[4] P.P. Chen, Q.R. Zhao, C.Y. Yan and X. Li, Promotional pricing and online business model choice in the presence of retail competition. Omega 94 (2020) 102085.

[5] K.W. Chiang, D. Chhajed and D.J. Hess, Direct marketing indirect profits: a strategic analysis of dual-channel supply chain design. Manage. Sci. 49 (2003) 1-20.

[6] J.B. Gu, F.Y. Fu and J. Ye, Joint optimization and coordination of fresh-product supply chains with quality-improvement effort and fresh-keeping effort. Qual. Technol. Quant. Manage. 18 (2020) 20-38.

[7] P.Y. Lee and Y.C. Dye, An inventory model for deteriorating items under stockdependent demand and controllable deterioration rate. Comput. Ind. Eng. 63 (2012) 474-482.

[8] W. Li, J. Chen, G. Liang and B. Chen, Money-back guarantee and personalized pricing in a Stackelberg manufacturer's dual-channel supply chain. Int. J. Prod. Econ. 197 (2018) 84-98.

[9] H. Lu and J.Y. Chen, Strategic motive for introducing internet channels in a supply chain. Prod. Oper. Manage. 23 (2014) $36-47$.

[10] R.E.A. Mueller, Ecommerce and entrepreneurship in agricultural markets. Am. J. Agric. Econ. 83 (2001) 1243-1249.

[11] S. Panda, M.N. Modak, S.S. Sana and M. Basu, Pricing and replenishment policies in dual-channel supply chain under continuous unit costs decrease. Appl. Math. Comput. 256 (2015) 913-929.

[12] S. Piramuthu and W. Zhou, RFID and perishable inventory management with shelf-space and freshness dependent demand. Int. J. Prod. Econ. 144 (2013) 635-640.

[13] B. Roy and B.C. Giri, A three-echelon supply chain model with price and two-level quality dependent demand. RAIRO:OR 54 (2020) 37-52.

[14] A. Roy, S.S. Sana and K. Chaudhuri, Joint decision on EOQ and pricing strategy of a dual channel of mixed retail and e-tail comprising of single manufacturer and retailer under stochastic demand. Comput. Ind. Eng. 102 (2016) 423-434.

[15] Z. Song and S. He, Contract coordination of new fresh produce three-layer supply chain. Ind. Manage. Data Syst. 119 (2019) $1-23$.

[16] X.C. Wang, M.M. Leng and P.L. Liang, Choosing an online retail channel for a manufacturer: Direct sales or consignment? Int. J. Prod. Econ. 195 (2018) 338-358.

[17] L. Zhang and J. Wang, Coordination of the traditional and the online channel for a short-life-cycle product. Eur. J. Oper. Res. 258 (2016) 639-651.

[18] G.F. Zhao, S.D. Wu, L. Liang and A. Dolgui, Lateral inventory transshipment problem in online-to-offline supply chain. Int. J. Prod. Res. 54 (2016) 1951-1963.

[19] Q. Zheng, P. Ieromonachou, J.T. Fan and L. Zhou, Supply chain contracting coordination for fresh products with fresh-keeping effort. Ind. Manage. Data Syst. 117 (2017) 538-559. 